\begin{tabular}{|c|c|}
\hline Title & MODULAR CONSTRUCTIONS MADE OF UHPC \\
\hline Author(s) & TUE, N.V. \\
\hline Citation & $\begin{array}{l}\text { Proceedings of the Thirteenth East A sia Pacific Conference on Structural Engineering and Construction (EA SEC-13), } \\
\text { September 11-13, 2013, Sapporo, Japan, F-3-5., F-3-5 }\end{array}$ \\
\hline Issue Date & 2013-09-12 \\
\hline Doc URL & http:/hdl. handle.net/2115/54384 \\
\hline Type & proceedings \\
\hline Note & $\begin{array}{l}\text { The Thirteenth East A sia Pacific Conference on Structural Engineering and Construction (EA SEC-13), September 11- } \\
\text { 13, 2013, Sapporo, Japan. }\end{array}$ \\
\hline File Information & easec13-F-3-5.pdf \\
\hline
\end{tabular}

Instructions for use 


\title{
MODULAR CONSTRUCTIONS MADE OF UHPC
}

\author{
N. V. TUE ${ }^{1 *}$ \\ ${ }^{1}$ Institute of Structural Concrete, Graz University of Technology, Austria
}

\begin{abstract}
UHPC (Ultra High Performance Concrete) is a high tech material with outstanding properties. Because of its need for special regard at production and casting an application in the precast industry is generally recommended. Furthermore, the costs of UHPC are nearly 10 times higher compared to ordinary concrete. For economic use of this high tech material, new design philosophies in concrete construction have to be developed. Suitable construction types and building methods are filigree, flexible and modular constructions with precast elements. This effectively combines the high-performance material properties and the special features of this new material with the demands for sustainability, fast construction progress and wide application. This contribution presents general considerations on modular UHPC constructions by introducing three recent examples of UHPC application. Finally this illustrates the high potential of UHPC for sophisticated constructions in both aspects, architecture and structural engineering.
\end{abstract}

Keywords: UHPC, modular construction, segmental bridge, dry joints

\section{INTRODUCTION}

UHPC with its inherent benefits of high compression strength and remarkable durability opens new possibilities in structural engineering. At the same time the increasing material and production costs of this innovative material call for the development of suitable construction types and beneficial building methods. Because of UHPC's high modulus of elasticity, compared with conventional concrete, very light and thin-walled cross sections with sufficient stiffness (light cross sections with high moments of inertia or arch and truss structures) are favorable. The modulus of elasticity-ratio between UHPC and structural steel of nearly a fourth indicates a classification of the construction concepts for UHPC structures between the construction concepts of conventional steel and concrete structures. If such light cross sections were realized in conjunction with prefabricated segmental construction, external prestressing and dry joints, new or adapted erection methods, which speed up construction progress or allow erections in restricted areas, are imaginable. Both, the material savings due to light cross sections and the benefits of fast and less environment effecting construction methods provide the way for an economic application of UHPC. Besides this, the remarkable durability of UHPC increases service life while costs for maintenance decrease. Finally

\footnotetext{
* Corresponding author: Email: tue@tugraz.at
} 
this unburdens our public budgets for infrastructure. The following three examples of recent UHPC projects, which are completed or in the last realization process, give an overview about efficient use of this innovative material and its economic application.

\section{ROAD BRIDGE WILD}

\subsection{Structure and construction Idea}

The first example is an arch road bridge in Austria (Reichel et al. 2010, Reichel et al. 2011). Due to the high stiffness of the arch structure a maximum utilization of the high compressive strength of UHPC was achieved. In contrast to this, beam structures for bridges with strict limits regarding deformation and vibration to achieve sufficient traffic safety never would reach such efficient utilization of compressive strength.

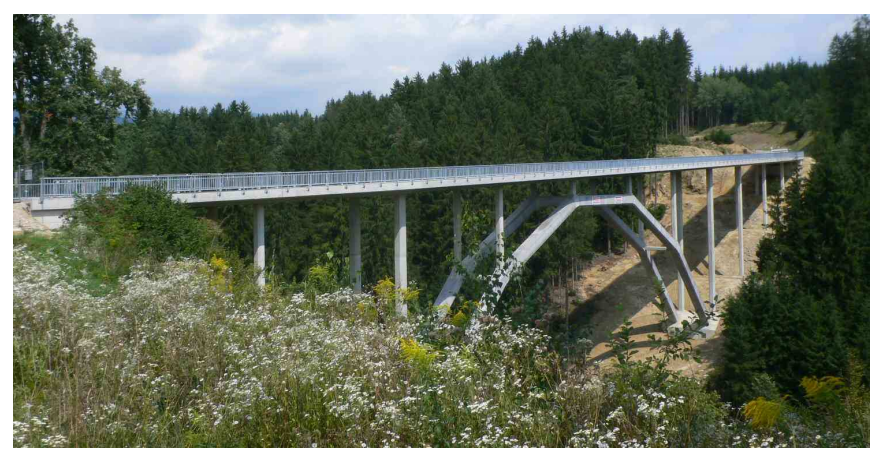

Figure 1: The road bridge Wild

The road bridge, which consists of a main arch span with $69 \mathrm{~m}$ and two foreland bridges, has a total length of $157 \mathrm{~m}$. At main span each of the two parallel arches is assembled of thin-walled (60 $\mathrm{mm})$ precast hollow box UHPC-segments and seven connection segments, so called knee-segments. They are prestressed together by external tendons running inside the arches. Because of very low bending and shear force in the arches no further ordinary reinforcement was needed in all UHPC-segments. Only the tensile capacity provided by the steel fibers ensures a save load bearing behavior. Furthermore, additional prestressing of the arch improves the stability. All further components of the bridge (columns, deck, foreland bridges) are made with cast in place normal strength concrete.

Because the bridge is crossing a deep gorge, the most efficient construction method for the arch was to combine the swivel-in method of arch construction with the light precast UHPC-segments. After completion of the foreland bridges, the several arch-segments are assembled in a vertical position using external tendons. The effort for equipment is minimal: a mobile crane for the manipulation and temporary ties for fixing the arch's position. The very light arch halves can easily be swiveled in. The hinge for swiveling is a simple steel bolt with a diameter of merely $80 \mathrm{~mm}$. The maximum tensile force in the temporary ties was about $2 \times 450 \mathrm{kN}$ and therefore $2 \times 4$ mono strands were sufficient. After joining the arch halves further tendons overlapping at the arch's crown were 
installed. Due to pouring the space between the knee-segment 1 and the arch abutment, the arch gets a rigid restraint.

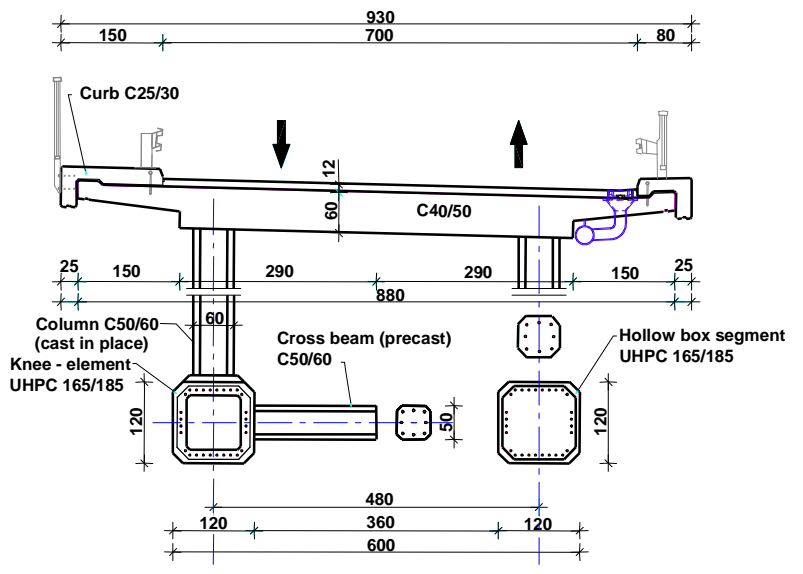

Figure 2: Cross section

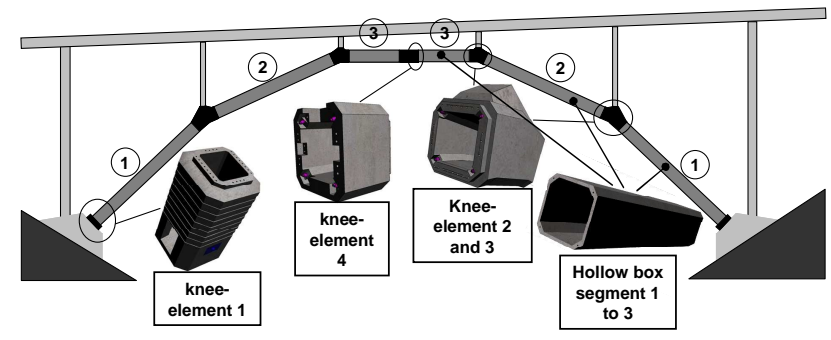

Figure 3: Assembly of the UHPC-Precast elements of the arch

The connection of the segments is realized by dry joints without any shear keys due to the low shear force. The strict requirements on the evenness of those joint surfaces to reach the required final arch geometry and to transfer the high compressive stresses as well as due to durability reasons could only be met by milling with a CNC-machine.

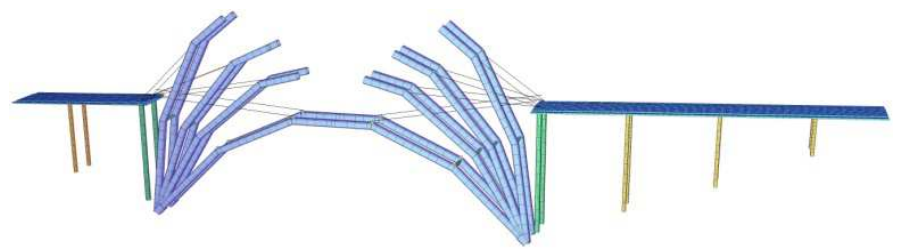

Figure 4: Principle of swivel-in method of arch construction

Further investigation was needed to transfer the concentrated loads due to lifting devices or other anchorage elements during assembling into the thin walled UHPC-elements. Even the needed space for conventional lifting devices was often not available. Only the more massive knee-segments allowed a fixing of temporary lifting devices. Also special considerations regarding storage, transportation and handling during assembly were necessary in order to avoid damage or harmful cracking of the filigree thin walled segments. Specially developed lifting devices and a mobile crane with two independent winches provide simple and fast adjustment in all directions for a 
proper assembling.

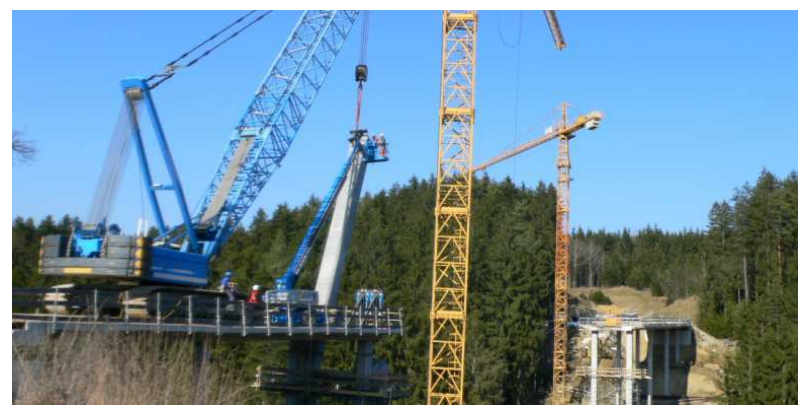

Figure 5: Vertical assembling of the arch

\subsection{Design, Detailing and Tests}

In order to analyse and design the arch, the material laws, the associated partial safety factors for UHPC and the design rules for ULS and SLS are gathered on the basis of (Schmidt et al. 2007, AFGC 2002, Reichel 2010). The buckling behavior of the segmental arch during the construction as well as in the final state was a special issue in the design and required the consideration of the stiffness change due to the gapping of the segmental joints. Therefore a special three-dimensional nonlinear calculation model based on beam elements was developed. This model was calibrated with the conducted full scale tests and other tests documented in literature.

The only steel fibre reinforced knee-segments with their complex shape at the bends of the segmental arch are sensitive discontinuity regions. Several actions such as anchoring and deviation of the prestressing tendons, bending moments induced by the columns as well as the shear and axial force in the compression zone of the segmental joint impact on those elements. Investigations by means of nonlinear and linear 3D-FE analysis delivered information about the expectable stress distribution.

Because present design codes and guidelines do not completely cover the use of UHPC in relation to the structure presented and the lack of experience, many experimental tests (including two full scale tests) gave answers to open questions for design and detailing (Freytag et al. 2009). The focus of the full-scale test was the load carrying behaviour in the region of the springing.

The used material models in the performed nonlinear 3D-FE analysis were calibrated and verified with the conducted tests. A recalculation of the full scale test confirmed the used material models.

\section{MODULAR TRUSS CONSTRUCTION}

\subsection{Structure and construction Idea}

The second example is an UHPC truss construction according to Lego-system. Because of the prevention of monolithic nodes all components of the construction can be industrially produced in concrete plant. 


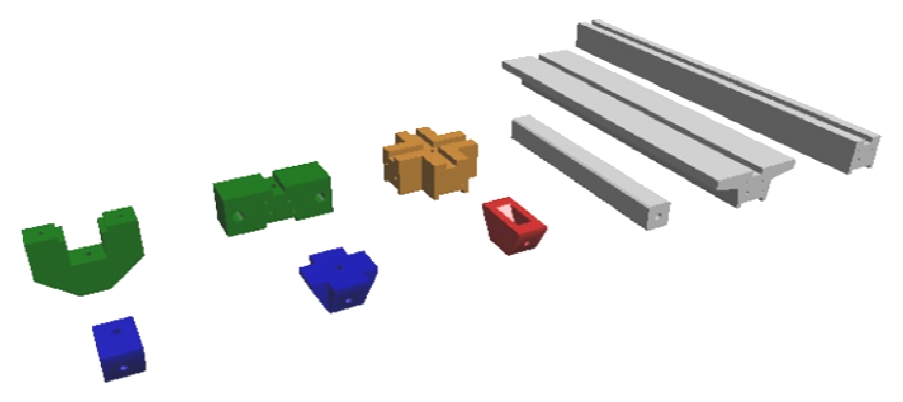

Figure 6: Elements of the truss construction

The connection between node elements and other components of the construction is designed as dry joints. Precast elements and dry joints allow a high flexibility of the construction in span and in construction height. With the variation of the prestressing forces the bearing capacity can be adapted in any order. Due to strict requirements on surface evenness the grinding of the node elements with CNC machine is the precondition for the realisation with dry joints. External prestressing tendons satisfy the requirements of ULS and SLS. The construction weight is only about $20 \%$ higher than comparable steel constructions and a non-destructive demounting of the construction is possible any time (Tue et al. 2010).

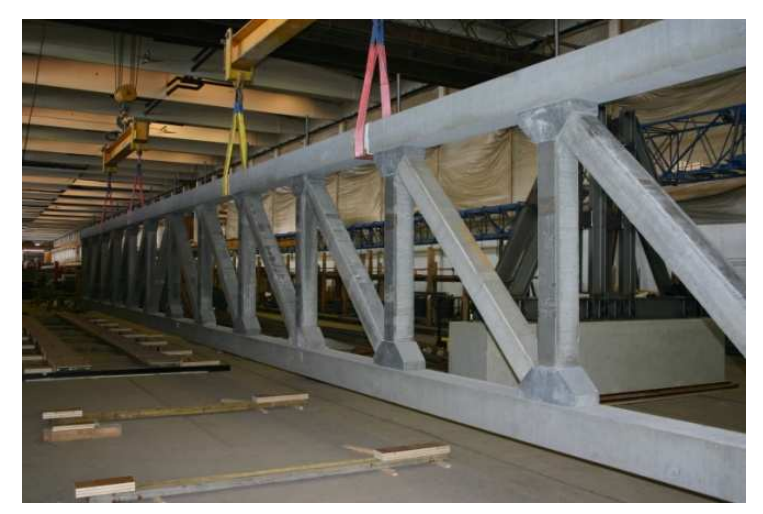

Figure 7: Truss construction for the full scale test

\subsection{Design, Detailing and Tests}

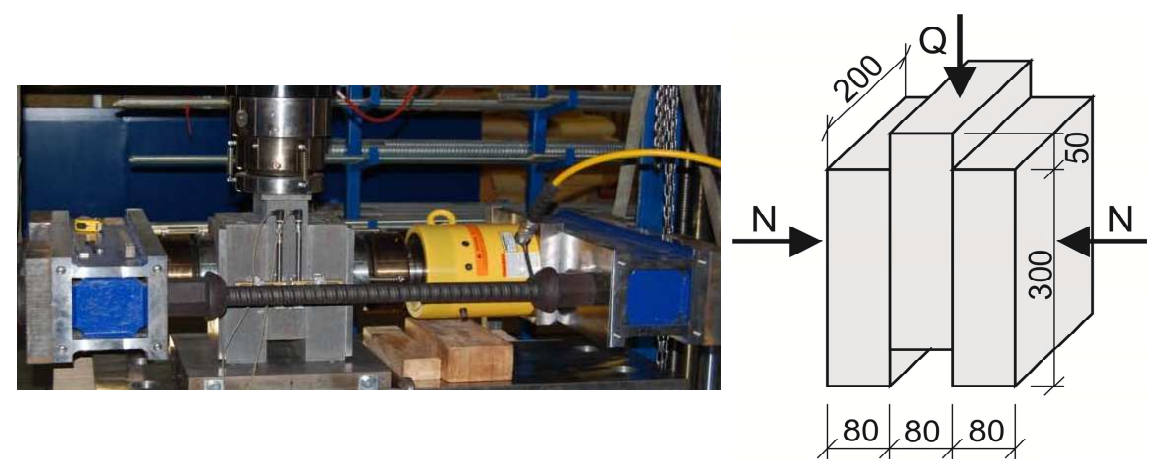

Figure 8: Test for determination of friction coefficient 
The most important detail of the construction is the node. In this element the transfer of compressive, tensile and shear forces is necessary. Due to the use of dry joints the friction coefficient between concrete surfaces is of high importance. Model tests considering different surface qualities are carried out in order to determinate the friction coefficient (Schoening et al. 2013) for the design of the shear bearing capacity. Additionally nonlinear calculations were conducted to analyse the stress state in the node element in ULS and SLS (Grube 2011). Furthermore, the influence of tolerances of the single components on the behavior of the whole construction was also analyzed in detail (Schwarz 2011).

\section{FOOTBRIDGE MARKKLEEBERG}

\subsection{Structure and construction Idea}

The third example is a hybrid construction for a pedestrian bridge in Markkleeberg near Leipzig to replace an about 10 years old wood arch bridge. An important design issue was to maintain the old arch shape, the clearance profile between bridge and river and the old abutments. Further demands on the design were aesthetic, a simple and fast erection, long service life and low effort for maintenance. These conditions can be perfectly matched by the proposed hybrid construction with UHPC. The two parallel arches of the new bridge consist of conventional steel tubes and a flat UHPC-deck slab as a tie between the arch springing, which is suspended from the steel arch by inclined but non-intersecting hangers. The deck slab is assembled of 10 precast UHPC-segments and the tensile force is compensated at each arch by exchangeable external tendons, which are running inside of the deck slab. There is no waterproofing or other surface treatment for the deck slab due to the excellent durability properties of UHPC required.

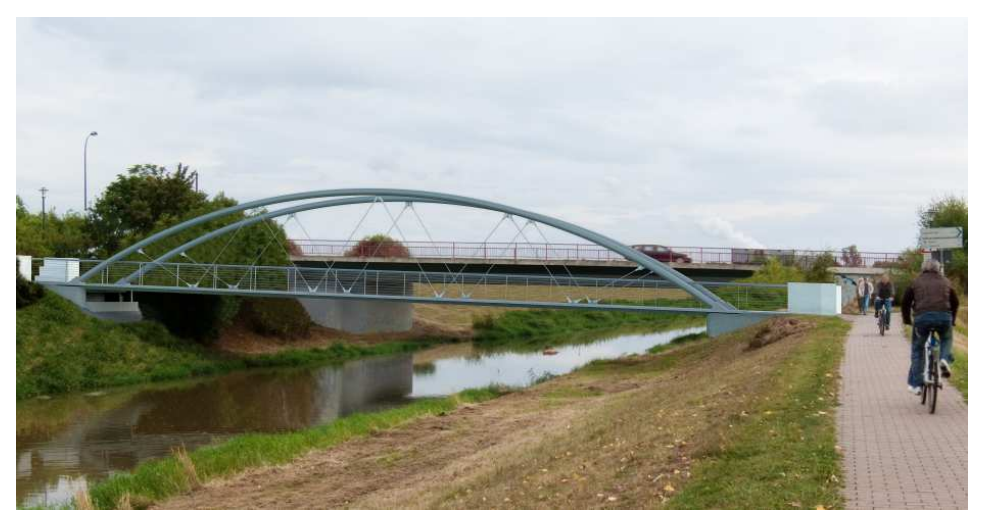

Figure 9: Hybrid footbridge Markkleeberg

The cross section has a width of $5.3 \mathrm{~m}$. By a distance between the webs of $4.2 \mathrm{~m}$ the thickness of the slab is only $8 \mathrm{~cm}$. In the line between the arch springing the slab is enlarged to so-called main girders which are $30 \mathrm{~cm}$ thick and inside of these main girders the tendons are positioned. Again, the joints between the precast segments are dry joints. A mechanical CNC-milling of the joint surface was not required, because the compressive stresses in longitudinal bridge direction are not so high. Therefore sufficient accuracy of the joint evenness could be reached be a highly precise 
steel formwork. To meet the durability requirement and a dense joint an additional elastomeric sealing between the precast segments was applied.

\subsection{Design and Tests}

Because the load bearing behavior of fibers reinforced structures depends on fibers orientation and distribution it is very difficult to guarantee the assumed design tensile strength in the produced segment. Furthermore the material costs increases significantly with increasing fibers content. Therefore in transverse direction a combination of fibers and ordinary reinforcement is used. Herewith a fiber content of only $1.0 \mathrm{Vol} .-\%$ is necessary for very small and not harmful crack widths, ensuring high durability adequate to the used UHPC. For bending design under ULS conditions only the ordinary reinforcement is sufficient and therefore the contribution of fibers is negligible.

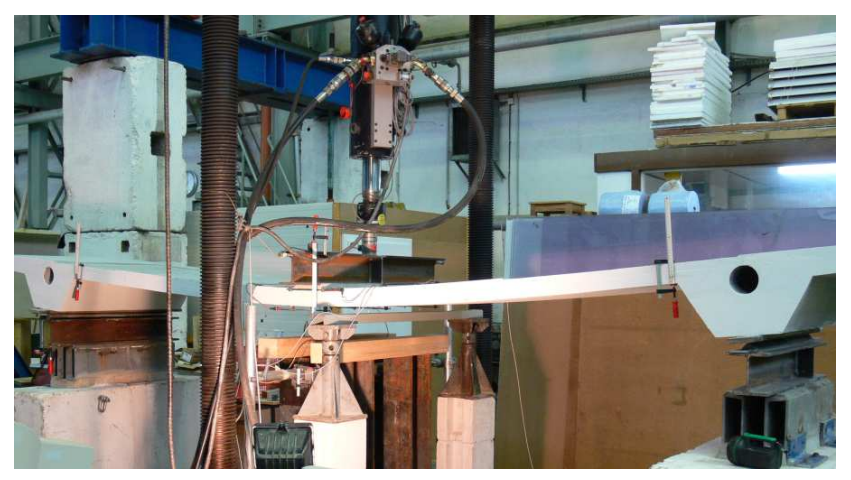

\section{Figure 10: Full scale test to determine the bearing capacity of lateral direction}

Because of the minor experience and missing codes for the design of UHPC structures, a full scale test in transverse direction was performed. A second issue of the test was to investigate the deformation behavior of the very slender deck slab at SLS, which was decisive for the design. This investigation was carried out under quasi permanent and rare loads and the development of the deformation was observed for 10 load cycles. After that the load was increased until load and finally failure. The load deformation behavior in the test indicates a brittle failure due to localization of the fracture process in one crack. However the ultimate bearing capacity is many times higher than required and the deformations at point of failure amounts more than $30 \mathrm{~cm}$. According to this, the failure will be indicated due to large deformations and therefore sufficient ductility can be assumed.

Because of the less space in the thin-walled segments the dimensions of the load bearing plates of the prestressing anchors must be reduced comparing to the technical approval for ordinary concrete. Therefore additional tests according ETAG 013 for the span anchors with reduced dimensions were performed. To reduce the construction time the new bridge will be assembled on one side of the river. After that the old bridge will be removed and the new bridge will be completely lifted into its final position by a mobile crane. 


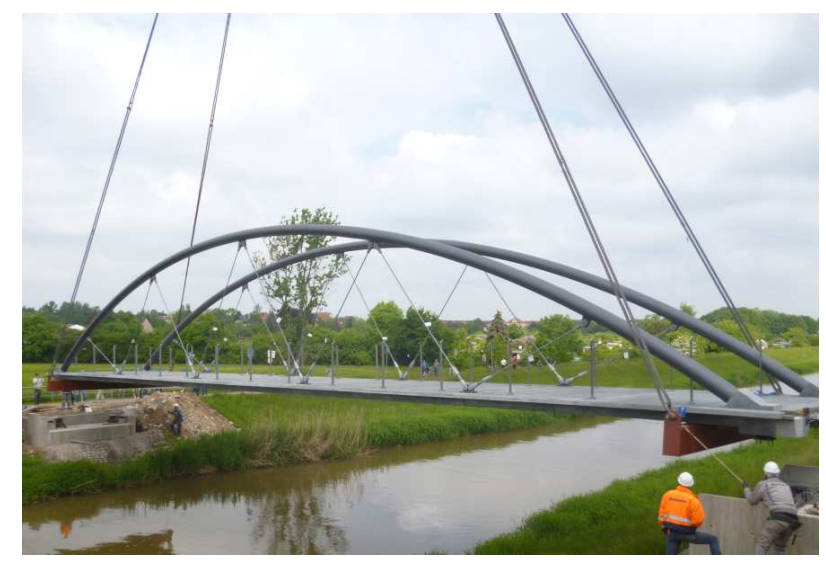

Figure 11: Assembly of the bridge with mobile crane

\section{CONCLUSIONS AND OUTLOOK}

The previously illustrated examples show, that an efficient and economical use of UHPC is possible. Especially the combination with filigree, flexible and modular segmental construction methods and the consequent involvement of all drawbacks and benefits regarding the special properties and features of this new building material offers a wide range of very promising solutions. Meanwhile a lot of experience could be gained with many completed pilot projects all over the world, which showing the wide variety of new possibilities. But the next big step is to cast all the experience and the results from research in recommendations or codes to implement UHPC as a building material in practice and furthermore to enhance the acceptance of clients and authorities.

\section{REFERENCES}

AFGC, 2002. Association Française de Génie Civil (AFGC) / Service d'études techniques des routes et autoroutes (SETRA): Bétons fibrés à ultra-hautes performances / Ultra High Performance Fibre-Reinforced Concretes. Recommandations provisoires / Interim Recommendations. Janvier 2002.

Freytag, B. et al. 2009. Großversuch WILD-Brücke - Versuchsgestützte Bemessung einer UHPC-Bogenbrücke. Betonund Stahlbetonbau 104 (3/2009): 134-144.

Grube, A 2011. Detailanalyse zum Tragverhalten von Trockenfugen in UHPC-Fachwerkträger. Master Thesis, TU Graz 2011.

Reichel, M. et al. 2009. UHPFRC-Prototype for a Flexible Modular Temporary High Speed Railway Bridge. BFUP 2009 / UHPFRC 2009 Actes / Proceedings, 2009: Marseille.

Reichel, M. et al. 2010. Road Bridge "Wild" - Application of the UHPFRC precast segmental construction method for an arch structure. 3rd fib International Congress, 2010: Washington.

Reichel, M. 2010. Forschungsbericht FFG-Projekt 819342. Endbericht Teil 1/6, Endbericht Teil 6/6. TU Graz, 2010.

Reichel, M. et al. 2011. Wildbrücke Völkermarkt - vorgespanntes Bogentragwerk aus UHFB-Segmentfertigteilen. Beton- und Stahlbetonbau 106 (11/2011): 760-769, 106 (12/2011): 827-835.

Schmidt, M. et al. 2007. Sachstandsbericht Ultrahochfester Beton. DAfStb Heft 561, Beuth, Berlin 2007.

Schoening, J. et al. 2013: Verbindungen von Fertigteilen aus UHPC. Bautechnik $\quad$ (90) 5/2013.

Schwarz, J. 2011. Statische Berechnungen zum modularen UHPC-Fachwerkträger, 2011. (unpublished).

Tue, N. et al. 2010. Innovative ultra-high performance concrete products in practice. Proceedings 54. Beton Tage, Ulm 2010. 